\title{
Determinación de la presencia de bacterias patógenas para el humano en aguas de riego en la cuenca alta de la sabana de Bogotá; D.C. Colombia
}

\author{
Determination of bacterial human pathogens in irrigation water of the \\ savannah of Bogota high watershed
}

Lucía Constanza Corrales Ramírez ${ }^{1}$ Ligia Consuelo Sánchez Leal ${ }^{1}$, Fabián Andrés Escucha Rodríguez ${ }^{2}$.

\section{Resumen}

Objetivo: Determinar la presencia de bacterias patógenas para el humano en aguas de riego en la cuenca alta de la Sabana de Bogotá, Colombia. Materiales y métodos: Se recolectaron 21 muestras en 8 municipios, 8 fueron seleccionadas de forma aleatoria para la determinación de coliformes totales mediante filtración por membrana, número más probable (NMP) para coliformes fecales, aislamiento en medios selectivos e identificación bioquímica con el sistema BDBBL CRYSTAL. Resultados: Se encontró contaminación fecal directa y/o difusa en el $41.7 \%$ de muestras y en el $58.3 \%$ restante flora normal acuático-terrestre. El porcentaje de E.coli hallado y el recuento de coliformes totales indican que el agua analizada no es apta para el uso agrícola y representa riesgo para la salud.

Palabras Clave: bacterias patógenas, contaminación fecal, E.coli.

\begin{abstract}
Objective: To determine the presence of bacterial human pathogens in irrigation water of the savannah of Bogota high watershed. Materials and methods: Samples were collected from 8 municipalities, 8 of which were randomly selected for a number of tests including detection of total coliforms via filtration membrane, Most Probable Number (MPN) for fecal coliforms; isolation on selective media and biochemical identification using the BD-BBL CRYSTAL system. Results: Direct or diffuse fecal contamination approached $41.7 \%$ of selected samples while aquatic-terrestrial normal flora the remaining 58.3\%. According to the percentage of E.coli and count of total coliforms, the analyzed water is not suitable for agricultural use and represents a risk for human health.
\end{abstract}

Key words: pathogenic bacteria, fecal contamination, E.coli.

'Docentes investigadores Universidad Colegio Mayor de Cundinamarca

${ }^{2}$ Estudiante Universidad Colegio Mayor de Cundinamarca

Correspondencia: lcorrales@unicolmayor.edu.co 


\section{Introducción}

La sabana de Bogotá, D.C. Colombia, basa su economía principalmente en industrias químicas y curtiembres como es el caso de Villapinzón, y en la agricultura. Las dos primeras generan gran cantidad de contaminación de afluentes del río Bogotá, que directa o indirectamente pueden llegar a ser utilizadas en la agricultura al abastecer sus sistemas de irrigación (1). Este uso puede implicar un riesgo para la salud de los agricultores y consumidores, riesgo que se incrementa por el desconocimiento de los agricultores sobre el manejo de las buenas prácticas agrícolas.

El uso correcto y responsable de aguas residuales en sistemas de riego puede tener beneficios como: el ahorro en el costo de los recursos hídricos, el crecimiento de la producción y el aumento en las oportunidades económicas: Sin embargo, se debe considerar que el uso de este recurso puede acarrear problemas de salubridad relacionadas con la carga contaminante de origen químico, físico y/o microbiológico.

L. Castro-Espinoza et al (2) afirma que la rápida urbanización incrementa los volúmenes de aguas residuales que se desechan, estas aguas representan una alternativa de bajo costo en la irrigación convencional de cultivos; dan soporte para la sobrevivencia y genera considerable valor agregado a la agricultura en las áreas peri-urbanas a pesar de los riesgos para la salud y para el medio ambiente asociados a esta práctica.

En Colombia una de las estructuras físico-naturales más intervenidas y fragmentadas por las acciones humanas es, sin ninguna duda, la Sabana de Bogotá, D.C. (1). El río Bogotá es su principal fuente hídrica y el receptor de los aportes domésticos de los habitantes de Bogotá, D.C y los municipios de la Sabana. El 90\% de la carga contaminante del río llega a través de los ríos Salitre o Juan Amarillo, Fucha y Tunjuelo. Un 30\% de este caudal proviene de la cuenca del Salitre, un 39\% del Fucha y un
$21 \%$ del Tunjuelo, estando compuesto el 10\% restante por los aportes combinados de las subcuencas de Torca, Conejera, Jaboque, Tintal y Soacha (3). De acuerdo con el estudio realizado por Campos Pinilla et al (4), se observa que la contaminación de origen doméstico genera un alto riesgo a nivel sanitario, debido a las altas concentraciones de microorganismos de origen fecal que se pueden encontrar.

De acuerdo con estudios realizados por el Ministerio de Ambiente, Vivienda y Desarrollo Territorial, el río Bogotá D.C., es una de las fuentes de agua más empleadas con fines agrícolas en la Sabana de Bogotá, D.C., además está caracterizada por la elevada presencia de contaminantes (5).

De igual forma los estudios realizados por L. Castro-Espinoza et al (2), han demostrado la capacidad de estas aguas residuales para dispersar inóculos capaces de transmitir enfermedades que van a parar a los cultivos agrícolas, siendo este un riesgo para la salud pública. Cuando se utilizan aguas residuales domésticas el problema por lo general es más de índole microbiológico (1). La calidad microbiológica de las aguas residuales suele ser medida por la concentración de dos principales indicadores; los coliformes fecales y los huevos de nematodos $(6,7)$.

No obstante el documento sobre reutilización de aguas residuales menciona que los criterios más importantes para establecer la calidad del agua se refiere sobre todo al contenido microbiológico ya que la presencia de ciertas bacterias y virus puede plantear problemas higiénico-sanitarios y la transmisión de enfermedades infectocontagiosas (8).

Por tal razón, es importante determinar la presencia o ausencia de microrganismos patógenos en las aguas utilizadas en la sabana de Bogotá, D.C y obtener información sobre cuáles de los agentes microbianos presentes son capaces de producir enfermedad, así como establecer la situación actual de los índices biológicos de contaminación. 
Este estudio permitió evaluar el cumplimiento del Decreto 1594 de 1984 que establece los criterios admisibles para el agua de uso agrícola y que establece que: «El Número más probable NMP de coliformes totales no deberá exceder de 5.000 cuando se use el recurso para riego de frutas que se consuman sin quitar la cáscara y para hortalizas de tallo corto” (9).

Los trabajos relacionados con aguas de riego realizados en el país han sido dirigidos a garantizar y cumplir las normas establecidas por el ICA e ICONTEC para recuento de patógenos humanos, coliformes, Salmonella y Shigella (10), lo que permite inferir que ninguno de estos estudios han sido destinados a prevenir enfermedades derivadas de la ocupación de los agricultores y sus familias (11).

\section{Materiales y métodos Muestreo}

La toma de muestras se realizó en ocho (8) municipios de la cuenca alta de la Sabana de Bogotá, D.C. de los cuales se seleccionaron y muestrearon 21 fincas, esta toma se efectuó en los puntos de entrada y salida de agua de los sistemas de riego, a su vez fueron escogidas al azar 8 de estas muestras para el estudio, una por cada municipio. Las muestras que provenian de pozo profundo, laguna, estanque etc. fueron tomadas a una profundidad de $50 \mathrm{~cm}$ aproximadamente (12).

\section{Métodos}

El proceso de investigación se llevó a cabo en dos etapas, en la primera se realizó un reconocimiento geográfico de la zona y una actividad de sensibilización y consentimiento de los productores acerca del proceso investigativo, en esta se abordaron temas sobre el efecto que puede tener el agua contaminada sobre los cultivos, los trabajadores y consumidores, objeto de interés de este trabajo de investigación.

La segunda etapa incluyó la selección, toma, transporte y procesamiento de las muestras. En esta se consideraron aspectos como: temperatura de transporte $\left(4^{\circ} \mathrm{C}\right)$, tiempo de transporte (no mayor de 3 horas) para evitar la alteración de la carga de microorganismos bacterianos; volumen y condiciones de toma de muestra (5 litros en recipiente estéril) y finalmente los medios para la siembra, aislamiento e identificación (12).

Las muestras fueron procesadas en los laboratorios de la Universidad Colegio Mayor de Cundinamarca, las técnicas utilizadas fueron: Número Más Probable de coliformes fecales, filtración por membrana para coliformes totales, aislamiento en medios selectivos e identificación bacteriana por el método BD BBL CRYSTAL.

\section{Procesamiento y cultivo de las muestras}

El aislamiento primario se realizó en agua peptonada al $0.1 \%$ y se incubó a $37^{\circ} \mathrm{C}$ durante 24 horas, la presencia de turbidez se tomó como resultado positivo. Como control se decidió tomar una muestra de agua del rio Bogotá, para tenerla como punto de referencia y correlacionar sus resultados con los obtenidos a partir de las aguas de riego. De igual forma se sembró E. coli ATCC, como control de viabilidad de los medios utilizados.

A cada muestra positiva se le realizaron las siguientes pruebas:

Siembra: se hizo en tubos de $16 \times 150 \mathrm{~mm}^{3}$ con agua peptona al 1.0\%, posterior incubación a $35^{\circ} \mathrm{C}$ durante $12-24$ horas, para favorecer el crecimiento de coliformes totales. Para el cultivo de coliformes fecales se sembró en tubos de $16 \times 150 \mathrm{~mm}^{3}$ con caldo bilis verde brillante al 2\%, con posterior incubación de 24-48 horas a $45^{\circ} \mathrm{C}$ para la determinación del Número Más Probable.

Para este proyecto el resultado se da por rango de > ó < de $5.000 \mathrm{NMP} / 100 \mathrm{~mL}$ de muestra y así evaluar el cumplimiento del Decreto 1594 de 1984 que se refiere a los criterios admisibles para el agua de uso agrícola y que establece: «El $N u$ mero más probable (NMP) de coliformes totales no 
deberá exceder de 5.000 cuando se use el recurso para riego de frutas que se consuman sin quitar la cáscara y para hortalizas de tallo corto".

Aislamiento: posterior a la incubación se realizó el repique de los tubos con crecimiento positivo en agar Mac Conkey, agar sangre, agar sangre con azida de sodio y agar King B, los cuales se incubaron a $37^{\circ} \mathrm{C}$ durante $18-24$ horas, a las colonias observadas se les realizó tinción de Gram e identificación por el método automatizado BDBBL CRYSTAL ${ }^{\mathrm{TM}}$.

Técnica de filtración por membrana: la técnica de filtración por membrana fue utilizada para la identificación y cuantificación de bacterias coliformes presentes. Se utilizó el medio Endo con sus respectivas membranas, la técnica se realizó teniendo en cuenta los parámetros establecidos por los Standard Methods for the Examination of Water and Wastewater y el trabajo de grado denominado "Elaboración de un protocolo para la identificación de nematodos fitopatógenos en el agua de riego de la sabana de Bogotá" presentado por Gerardo Rodríguez con algunas modificaciones.

\section{Socialización de resultados}

Los resultados obtenidos fueron socializados con cada uno de los agricultores que participaron en el proyecto, con el objetivo de facilitar la implementación de estrategias de mejoramiento por parte de éstos, para ofrecer una mejor calidad en los productos y prevenir enfermedades trasmitidas por aguas contaminadas en forma directa a los operarios e indirecta por contaminación en las frutas y hortalizas.

\section{Resultados}

Los sistemas de riego utilizados, el origen y porcentaje del agua usada en los sistemas de riego, el tiempo de exposición al agua de riego de las 8 fincas analizadas se representan en las tablas 1,2 y 3 .
Tabla 1. Porcentaje de los sistemas de riego utilizados en las fincas analizadas.

\begin{tabular}{lcc}
\multicolumn{1}{c}{ Sistema de Riego } & $\mathbf{N}^{\circ}$ de Fincas & Porcentaje \\
\hline Por superficie & 3 & $37.5 \%$ \\
Por goteo & 5 & $62.5 \%$ \\
Por aspersión & 0 & $0 \%$ \\
Por micro-aspersión & 0 & $0 \%$ \\
Riego subterráneo & 0 & $0 \%$ \\
\hline
\end{tabular}

Fuente: autores

El porcentaje se efectuó a partir del total de las 8 fincas seleccionadas al azar para este proyecto.

Tabla 2. Origen y porcentaje del agua usada en los sistemas de riego en las 8 fincas de la cuenca alta de la Sabana de Bogotá, D.C.

\section{Origen del agua $\quad \mathbf{N}^{\circ}$ de fincas Porcentaje}

\begin{tabular}{lcc} 
Rio Bogotá & 0 & $0 \%$ \\
\hline Pozo profundo & 2 & $25 \%$ \\
\hline $\begin{array}{l}\text { Acueducto veredal } \\
\text { Quebradas }\end{array}$ & 1 & $12.5 \%$ \\
$\begin{array}{l}\text { Combinación* Utiliza- } \\
\text { ción de agua de más de } \\
\text { una fuente de origen }\end{array}$ & 2 & $25 \%$ \\
\hline
\end{tabular}

Fuente: autores

Tabla 3. Tiempo de exposición con el agua de riego.

\begin{tabular}{llcc} 
Municipio & \multicolumn{1}{c}{$\begin{array}{c}\text { Nombre } \\
\text { de la finca }\end{array}$} & $\begin{array}{c}\text { Número de } \\
\text { trabajadores }\end{array}$ & $\begin{array}{c}\text { Tiempo de } \\
\text { exposición } \\
\text { horas al día }\end{array}$ \\
\hline Villapinzón & Verde Life & 2 & 3 horas \\
Chocontá & El Laurel & 1 & 2 horas \\
Suesca & $\begin{array}{l}\text { La Puerta De } \\
\text { Oro }\end{array}$ & 1 & 2 horas \\
Sesquile & El Campito & 1 & 3 horas \\
\hline Gachancipá & Lechuga y Vida & 1 & 1 hora \\
Tocancipá & $\begin{array}{l}\text { Inversiones } \\
\text { Jacaranda C.I. }\end{array}$ & 1 & 1 hora \\
Cajicá & Elda & 1 & 2 horas \\
Chia & El Cerezo & 1 & 2 horas \\
\hline
\end{tabular}

Fuente: autores 
Los resultados de la determinación del número más probable de coliformes fecales, las bacterias aisladas e identificadas en las aguas de riego y el porcentaje de bacterias aisladas en las aguas de riego se presentan en las tablas 4 a la 7.

Tabla 4. Determinación de número más probable para coliformes fecales en las aguas de riego.

\begin{tabular}{llcl}
\multicolumn{1}{c}{ Municipio } & \multicolumn{1}{c}{$\begin{array}{c}\text { Nombre } \\
\text { de la finca }\end{array}$} & $\begin{array}{c}\text { Número Más Probable } \\
\text { (NMP) }\end{array}$ & Resultado \\
\hline Villapinzón & Verde Life & $0,0 / \mathrm{NMP}$ & Negativo \\
Choconta & El Laurel & $0.0 / \mathrm{NMP}$ & Negativo \\
\hline Suesca & La Puerta de Oro & $0,0 / \mathrm{NMP}$ & Negativo \\
\hline Sesquilé & El Campito & Negativo \\
\hline Gachancipa & Lechuga y Vida & $0,0 / \mathrm{NMP}$ & Negativo \\
\hline Tocancipa & $\begin{array}{l}\text { Inversiones Jacaranda } \\
\text { C.I. Ltda }\end{array}$ & $0,0 / \mathrm{NMP}$ & Negativo \\
\hline Cajicá & El Progreso & $0,0 / \mathrm{NMP}$ & Negativo \\
\hline Chía & El Cerezo & $0,0 / \mathrm{NMP}$ & Negativo \\
\hline
\end{tabular}

Fuente: autores

Tabla 5. Determinación de coliformes totales mediante la técnica filtración por membrana.

\begin{tabular}{llll}
\multicolumn{1}{c}{ Municipio } & Nombre de la finca & $\begin{array}{c}\text { Recuento de colonias filtración de } \\
\text { membrana }\end{array}$ & \multicolumn{1}{c}{ Resultado } \\
Villapinzón & Verde Life & $\begin{array}{l}\text { Colonias rosadas con brillo verde } \\
\text { metálico, incontables. }\end{array}$ & Positivo \\
Choconta & El Laurel & $\begin{array}{l}\text { Colonias verde dorado con brillo } \\
\text { metálico, incontables }\end{array}$ & Positivo \\
\hline Suesca & La Puerta De Oro & $\begin{array}{l}\text { Colonias verde dorado con brillo } \\
\text { metálico, incontables }\end{array}$ & Positivo \\
\hline Sesquilé & El Campito & $\begin{array}{l}\text { Colonias verde dorado con brillo } \\
\text { metálico, incontables }\end{array}$ & Positivo \\
\hline Gachancipa & Lechuga Y Vida & $\begin{array}{l}\text { Colonias cremosas de color rosado, } \\
\text { incontables }\end{array}$ & Negativo \\
\hline Tocancipa & $\begin{array}{l}\text { Inversiones Jacaranda } \\
\text { C.I. Ltda }\end{array}$ & $\begin{array}{l}\text { Colonias cremosas de color rosado, } \\
\text { incontables. }\end{array}$ & Negativo \\
\hline Cajicá & El Progreso & $\begin{array}{l}\text { Colonias verde dorado con brillo } \\
\text { metálico, incontables }\end{array}$ & Positivo \\
\hline Chía & El Cerezo & $\begin{array}{l}\text { Colonias cremosas de color rosado, } \\
\text { incontables }\end{array}$ & Negativo \\
\hline
\end{tabular}

Fuente: autores 
Tabla 6. Bacterias aisladas e identificadas en las aguas de riego.

\begin{tabular}{|c|c|c|c|}
\hline Municipio & Nombre de la finca & Microorganismo aislado & $\%$ de Confiabilidad \\
\hline Villapinzón & Verde Life (lechuga) & Escherichia coli & $99.9 \%$ \\
\hline Choconta & El Laurel (fresas) & $\begin{array}{c}\text { Escherichia coli Bacillus } \\
\text { subtilis }\end{array}$ & $\begin{array}{l}99.9 \% \\
90.0 \%\end{array}$ \\
\hline Suesca & $\begin{array}{c}\text { La Puerta de Oro (horta- } \\
\text { lizas) }\end{array}$ & $\begin{array}{c}\text { Aeromonas hydrophila } \\
\text { Escherichia coli }\end{array}$ & $\begin{array}{l}93.3 \% \\
99.9 \%\end{array}$ \\
\hline Sesquile & El Campito (tomate) & $\begin{array}{c}\text { Escherichia coli } \\
\text { Aeromonas hydrophila }\end{array}$ & $\begin{array}{l}99.9 \% \\
99.6 \%\end{array}$ \\
\hline Gachancipa & Lechuga y Vida & Aeromonas hydrophila & $99.8 \%$ \\
\hline Tocancipa & $\begin{array}{l}\text { Inversiones Jacaranda C.I. } \\
\text { Ltda (Ornamentales) }\end{array}$ & Aeromonas hydrophila & $99.9 \%$ \\
\hline Cajicá & El Progreso & $\begin{array}{l}\text { Escherichia coli. } \\
\text { Aeromonas hydrophila }\end{array}$ & $\begin{array}{l}99.9 \% \\
88.6 \%\end{array}$ \\
\hline Chía & El Cerezo (lechuga) & Aeromonas hydrophila & $99.7 \%$ \\
\hline
\end{tabular}

Fuente: autores

Tabla 7. Porcentaje de bacterias aisladas en las aguas de riego.

\section{Cepas Aisladas} $\mathrm{N}^{\circ}$ de Fincas

Porcentaje

E. coli

Areomonas hydrophila

Bacillus subtilis

Total 5

$41,7 \%$

Fuente: autores

\section{Discusión}

Una de las principales fuentes económicas de la Sabana de Bogotá, D.C. es la agricultura, donde las fuentes hídricas para el abastecimiento de sistemas de regadío son sin duda el rio Bogotá como primera medida, quebradas cercanas al rio (acueductos veredales) o afluentes del río Bogotá, nacederos y explotación de pozos profundos, que de una $\mathrm{u}$ otra manera pueden estar contaminadas o llegar a contaminarse de forma directa o difusa por los vertimientos de aguas residuales domésticas, vertimientos industriales (curtiembres), vertimientos químicos, elaboración de pozos sépticos, la explotación ganadera, el pastoreo y escorrentía de agua en épocas de lluvia.

Los sistemas de riego utilizados y la calidad del agua son un factor importante en la incidencia y prevalencia de muchas enfermedades sanitarias y fitosanitarias, situación que amerita la realización de estudios sobre patógenos presentes en aguas de riego $(13,14)$.

En el momento de la encuesta y la sensibilización, algunas fincas notifican no seguir en el proceso, sin justificar dicha decisión. En la observación etnográfica se encontró que algunas de éstas utilizan aguas tomadas directamente del río Bogotá para el riego de sus cultivos.

La investigación se llevó a cabo en época de lluvia, situación que puede afectar la concentración de bacterias halladas en el estudio, como puede suceder en el caso de aguas de escorrentía contaminadas con desechos de origen animal generadas por el pastoreo vacuno cercano a quebradas, lagunas o acuíferos. 
El acercamiento con los agricultores facilitó el intercambio cultural y de conocimientos sobre agricultura permitiendo aportar argumentos que ayudan a la elaboración de pautas en la prevención de enfermedades transmisibles por aguas de riego contaminadas, y contribuir al mejoramiento de la calidad de los productos agrícolas y los ambientes laborales para los agricultores.

Durante el proceso de recolección de la información se hallaron algunas inconsistencias con respecto al número de trabajadores en algunos de los cultivos, ya que en el momento de la toma de muestra el número de trabajadores presentes en el cultivo no coincidía con la información reportada en la encuesta por el dueño. En el proceso se toman 21 muestras de los 8 municipios de la cuenca alta de la sabana de Bogotá, D.C, de estas se seleccionan 8 al azar, una por cada municipio, a las cuales se les realizaron las técnicas y procedimientos estandarizadas para este tipo de análisis.

El porcentaje de E.coli encontrado evidencia contaminación fecal cercana a la fuente de abastecimiento de agua para los sistemas de riego, como lo indica el documento de la FAO (15). Sin embargo, la presencia de $E$. coli aunque es un parámetro que determina la contaminación fecal, no indica patogenicidad por sí misma, se requiere realizar la serotipificación de las cepas aisladas y conocer a qué virotipo pertenece y cuál es su potencial patógeno. De otro lado, el hecho de encontrar Aeromonas hydrophila en alto porcentaje, genera una alerta por cuanto este microorganismo posee una alta carga de factores de patogenicidad y virulencia los cuales le han permitido ser causante de diversos procesos infecciosos que van desde los más comunes como infección localizada en piel y gastroenteritis, hasta celulitis, mionecrosis, bacteremias y septicemias tanto en personas inmunocomprometidas como inmunocompetentes, procesos que se complican aún más por la resistencia a antibióticos que ya se han descrito (16 - 17).

Los resultados obtenidos en la determinación del NMP para coliformes totales permite deducir que las aguas objeto de análisis se pueden utilizar para "riego de frutas que se consuman sin quitar la cáscara y para hortalizas de tallo corto", de acuerdo con el decreto 1594. De otro lado, al correlacionar los resultados obtenidos en la carga de coliformes fecales y la detección de $E$. coli entre la muestra control (agua tomada directamente del rio Bogotá) y las muestras tomadas para el estudio, se observa una diferencia marcada ya que el control muestra el resultado de un agua no apta para ningún uso. Esta observación permite inferir que la filtración del agua que se lleva a cabo por procesos naturales desde el rio Bogotá, hasta la fuente hídrica de la cual se abastece el cultivo, disminuye considerablemente la carga de bacterias coliformes.

Se observa correlación entre los resultados obtenidos en relación con la presencia de coliformes y la falta de vigilancia por parte de las entidades municipales y departamentales, la inexistencia de medidas para la potabilización y la depuración de aguas residuales y el desconocimiento de los agricultores sobre los riesgos que conlleva el uso de aguas contaminadas, situación que facilita la diseminación de infecciones y enfermedades por el uso de aguas no aptas para el riego de hortalizas, legumbres y frutas de consumo directo (18), pese a que existen normativas que regulan el uso de estas aguas.

Las fincas que no quisieron atender o participar en el proyecto abastecen sus aguas de riego con agua directa del rio Bogotá, una de las fuentes más baratas para el desarrollo de los cultivos y principal suministro de aguas de riego a lo largo de la Sabana de Bogotá estableciendo un alto riesgo de salubridad debido a su alta carga contaminante.

Para mejorar la inocuidad de los productos generados a partir del uso con aguas de riego que no cumplen con los requerimientos necesarios de salubridad se sugiere someter éstas a un proceso de purificación antes de ser utilizadas en la agricultura mediante la creación de trampas para captación de agua, humedales artificiales o en su defecto el 
desarrollo de plantas de tratamiento como medida para la disminución de desechos químicos, físicos y microbiológicos, y de esta manera mejorar la calidad de sus productos (19). En este mismo sentido la Organización Mundial de la Salud, publicó las guías para el uso seguro de aguas residuales en la agricultura, las cuales deben encontrar el balance justo entre la minimización de riesgos para la salud pública y las ventajas de usar recursos escasos (20).

\section{Referencias}

1. Corporación Autónoma Regional de Cundinamarca (CAR). evaluación ambiental y plan de gestión ambiental. Fondo para las Inversiones Ambiéntales en la cuenca del Río Bogotá (FIA). República de Colombia. 2008.

2. L. Castro-Espinoza et al, Patógenos emergentes como restricción para el reuso de las aguas residuales municipales tratadas de Cd. Obregón, Sonora, Instituto Tecnológico de Sonora, 5 de Febrero 818 Sur, Colonia Centro, Cd. Obregón, Sonora, México C.P. 85000. En Revista Latinoamericana de Recursos Naturales.2009; 5 (1): 9-21.

3. Arjona, Fabio. Molina, Giovanni. Castro, Luis Fernando. Et al. El caso de Colombia. Comisión Económica para América latina y el Caribe. División de Medio Ambiente y Asentamientos Humanos. [Sitio en internet]. Disponible en: http://www. eclac.cl/publicaciones/xml/8/11048/lcl1690e_4.pdf Consultado el 16 de abril de 2012 .

4. Claudia Campos-Pinilla, et al. Comportamiento de los indicadores de contaminación fecal en diferente tipo de aguas de la sabana de Bogotá (Colombia) Universitas Scientiarum; 2008; 13 (2).

5. Ministerio de Ambiente, Vivienda y Desarrollo Territorial .Acuerdo 432006 Rio Bogotá. Por el cual se establecen los objetivos de calidad del agua para la cuenca del río Bogotá a lograr en el ańo 2020. Bogotá: Corporación autónoma regional de Cundinamarca (CAR). 2006.

6. Bitton, Gabriel. wastewater microbiology. wiley liss. $3^{\text {a }}$ Edición. Estados Unidos de América. 2005.

7. Rodríguez, Hugo. Validación interna de un método de cuantificación de coliformes totales en aguas para riego agrícola. Universidad Colegio Mayor de Cundinamarca. ICA LANIA. 2008.

8. Reutilización de aguas residuales. [Sitio en internet] Disponible en: http://www.agua.uji.es/pdf/leccionRH28.pdf consultado el 7 de abril de 2012.
9. Decreto colombiano número 1594 de 1984. Por el cual se decreta. Usos del agua y residuos líquidos.

10. Ministerio de agricultura y desarrollo rural. Decreto 4765 de 2008. Por el cual se modifica la estructura del Instituto Colombiano Agropecuario, ICA, y se dictan disposiciones. República de Colombia.

11. Arcos Pulido, Mireya del Pilar. Ávila de Navia, Sara Lilia. Estupiñán Torres, Sandra Mónica. Gómez Prieto, Aura Cristina. Indicadores microbiológicos de contaminación de las fuentes de agua. Universidad Colegio Mayor de Cundinamarca. Colombia. 2005.

12. American Public Health Association (APHA). Standard methods for examination of water and wastewater. 20th edition. American Public Health Association/American Water Works, Asociation/Water Environment Federation. Washington, D.C., United States. 1998; 1500 págs.

13. Consejo Nacional de Política Económica y Social (CONPES). Departamento Nacional de Planeación. Estrategia para el manejo del rio Bogotá. Documento 3320. Republica de Colombia. 2004. [Sitio en internet] Disponible en: http://www.dnp. gov.co/Portals/0/archivos/documentos/Subdireccion/Conpes/3320.pdf consultado el 15 de abril de 2012.

14. Organización para la Agricultura y la Alimentación (FAO). Agua y cultivos. Logrando el uso óptimo del agua en la agricultura. Documento. Roma. 2002.

15. FAO. Wastewater characteristics and effluent quality parameters Disponible en: http://www.fao.org/docrep/T0551E/ t0551e03.htm\#1.3.2 parameters of agricultural significance, consultado el 26 de agosto de 2012.

16. Emerging issues in water and infectious disease. World Health Organization 2003. [Sitio en internet]. Disponible en: http:// www.who.int/water_sanitation_health/emerging/emerging. pdf Consultado el 31 de Marzo de 2012.

17. Skwor T, Shinko J, Augustyniak A, Gee C, Andraso G. Aeromonas hydrophila and Aeromonas veronii predominate among potentially pathogenic ciprofloxacin and tetracycline resistant isolates of Aeromonas in Lake Erie. Appl Environ Microbiol. Rockford University, Department of Chemical and Biological Sciences, Rockford, IL 61108. 2013 Nov 15.

18. João P. S. Cabral. Water Microbiology. Bacterial Pathogens and Water. International Journal of Environmental Research and Public Health. 3657:3703. 2010.

19. FAO CORPORATE DOCUMENT REPOSITORY. Water quality for agriculture. Disponible en: http://www.fao.org/ docrep/003/T0234E/T0234E01.htm

20. Organización Mundial de la Salud. El Uso de aguas residuales. Disponible en: http://www.who.int/water_sanitation_health/ wastewater/es/ 10 de septiembre de 2012, 11:00 am. 